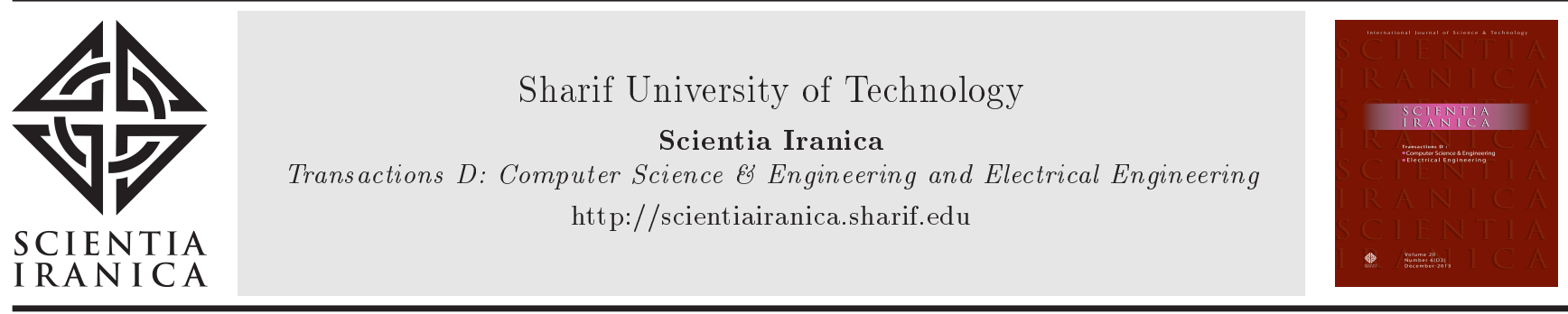

\title{
Polygonal tubular linear permanent magnet generator analysis and experimental test
}

\author{
S. Arslan ${ }^{\mathrm{a}, *}$ and O. Gürdal ${ }^{\mathrm{b}}$ \\ a. Department of Electrical, Organized Industrial Zone Vocational High School, Harran University, Sanliurfa, Turkey. \\ b. Gazi University, Faculty of Technology, Department of Electrical and Electronic Engineering, Ankara, Turkey. \\ Received 19 December 2018; received in revised form 26 July 2019; accepted 2 September 2019
}

\author{
KEYWORDS \\ Linear generator; \\ Tubular linear \\ machine; \\ Linear machine; \\ Free-piston linear \\ generator; \\ Generator \\ ANSYS Maxwell; \\ MATLAB GUI tool.
}

\begin{abstract}
Free piston generators are of interest due to their efficiency, compact construction, and multiple options for combustion. Much of the research into this type of generator has been facilitated by highly-developed internal combustion engine technology. This study was concerned with the design and application of tubular generator. The design model was developed using the matrix laboratory graphical user interface programming tool, and the designed interface was of dynamic type. The sizing of the generator was determined in accordance with the main parameters specified via the interface. In addition, as a benefit of using sizing data, the automatic geometry was formed and analyzed using ANSYS Maxwell software. The magnets and the dynamic part of the tubular-structured generator were shaped polygonally. Numerical analyses were made by adopting the finite element method in the software and construction of the prototype model was based on the results from these findings. The generator was excited by use of the crank rod mechanism to imitate the conditions of a functioning free piston mechanism. Current and voltage values were obtained at mechanical frequencies of $10 \mathrm{~Hz}$ and $20 \mathrm{~Hz}$, and this data was subsequently analyzed. Global code translation was given in attachment in order to allow communication between the ANSYS Maxwell and MATLAB GUI software.
\end{abstract}

2022 Sharif University of Technology. All rights reserved.

\section{Introduction}

Although electric vehicles offer zero emissions, they introduce range and charging difficulties. For this reason, hybrid vehicles offer many advantages in the short and medium terms, including energy savings and increased range in comparison to electric vehicles. In hybrid vehicles, range shortfalls can be overcome by

*. Corresponding author. Tel.: $+9(0$ 414) 31830 00; Fax: $+9(0$ 414) 3183228

E-mail addresses: serdalarslan@harran.edu.tr (S. Arslan); og.osman.gurdal@gmail.com (O.Gürdal)

doi: $10.24200 /$ sci.2019.50094.2739 installing additional equipment on the automobile. For example, when a vehicle is going downhill or braking, a regenerative system can produce electricity from the kinetic energy of the vehicle. In addition to these applications, linear generators are used in hybrid or electric vehicle suspension systems for power generation and minimization of road-induced vibrations. Other possibilities involve the use of linear generators to continuously charge battery groups using a free piston mechanism, known as a 'range extender'.

In addition, any fuel source such as gasoline, diesel, Liquefied Petroleum Gas (LPG), ethanol, biogas, etc., can be converted into mechanical energy; this allows electricity to be generated not only using in-vehicle technology but also internally or externally 


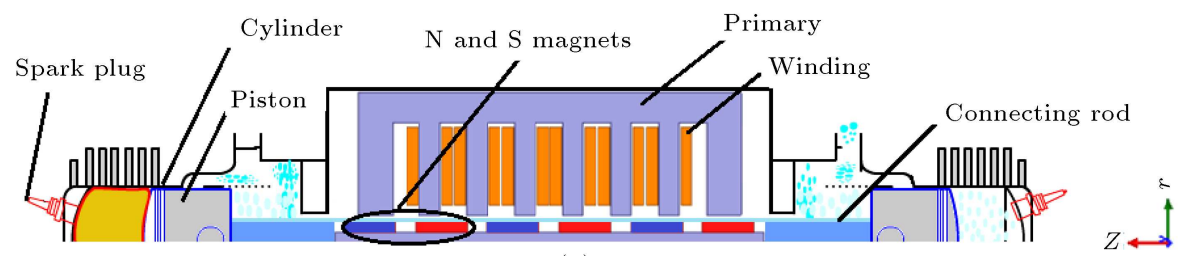

(a)

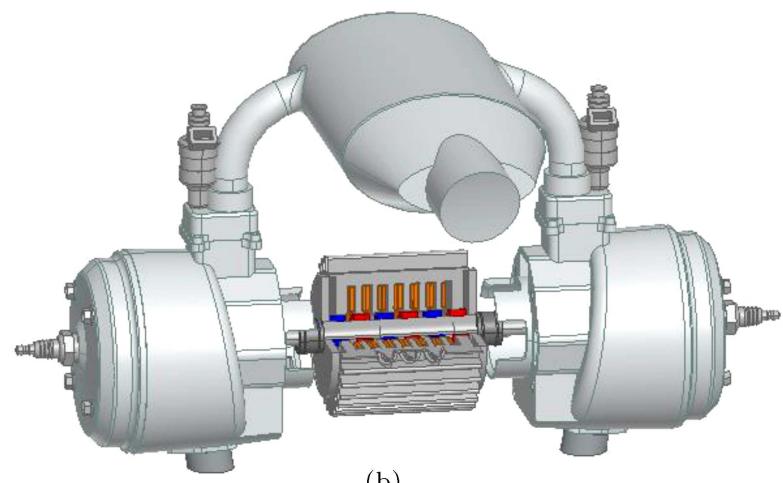

(b)

Figure 1. Free piston tube-type linear alternator: (a) Two-Dimensional (2D rz) view and (b) a cut-away view of the tubular-type linear generator with Free Piston Engine (FPE) in Three-Dimensional (3D) view.

by means of combustion systems. In conventional combustion engines, torque is generated by the piston movement and the crankshaft mechanism. However, in free piston systems, the piston can be designed so as to move along a single rod, thereby producing the forward and backward motions of the engine cycle. This motion energy is then converted to electric energy by means of a linear generator. Furthermore, this type of generator can work as an electric motor to provide start-up. Three different configurations are generally used for designing Free Piston Engines (FPE) in hybrid vehicles; these en gines consist of single piston, opposed piston, and dual piston structures. Each piston type can be combined into individual modules to form a single unit, allowing the desired power to be increased. These designs are realized by considering the required mechanical power, velocity, and stroke length. The single piston structure is inherently unbalanced, requiring the use of balancing weights, etc., and is not preferred for this reason. The opposed piston configuration is balanced, with little heat transfer losses, and constitutes a vibration-free design [1]. The double-piston structure creates a strong impulse at each oscillation and is vibratory and difficult to control, although it is more efficient [2].

Once the piston is at the end of compression stroke, the spark plug fires again to repeat the cycle. It is called a two-stroke engine because a two-stroke engine is an internal combustion engine that completes the process cycle in one revolution of the crankshaft. A four-stroke engine differs in that there are separate intake, compression, combustion, and exhaust strokes.
In the FPE design, opposing cylinders are connected by a single rod (Figure 1). In conventional engines, a separate electric motor is employed to turn the engine over and facilitate initiation. The hybrid vehicle differs in that the first linear movement, or stroke, is achieved by operating the machine as a motor. However, due to the high compressive forces encountered, the fixed current of the stator windings provides insufficient force to initiate single-shot initiation. In order to address this problem, linear machines with different geometric structures have been considered. Generators using free piston applications produce undesirable asymmetric forces, and this characteristic precludes the use of flat linear generators. Tubular structures are preferred since they generate a higher electromotive force (emf) and produce less leakage than flat structures. Tubular structures also allow the fixtures between (normally) attracting high forces to be balanced, produce high thrust, avoid the end effect (associated with the end winding of the flat linear generator), provide excellent servo characteristics, negate the need for motion conversion mechanisms to eliminate mechanical losses, and increase reliability.

A double-acting Free Piston Linear Generator (FPLG) has been designed and implemented at West Virginia University [3]. An opposed piston FPLG was developed using the cylinders of a Kawasaki 300sx motor [4]. At Sandia National Laboratory, an opposed piston FPLG was constructed that operated using a variety of hydrogen-containing fuels [5,6]. An application involving a dual piston FPLG for hybrid vehicles was successfully implemented at the Petronas 


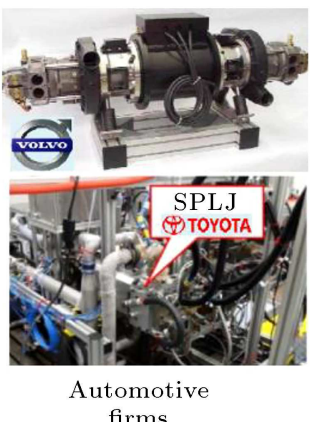

firms
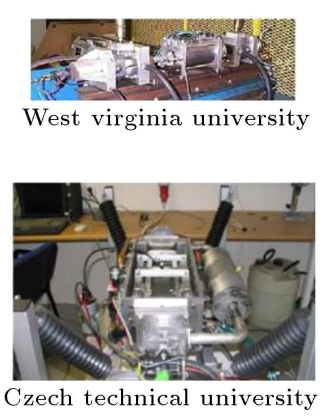

Linear

injector cylinder alternator cylinder injector

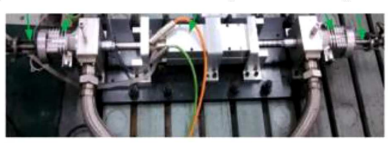

Chongqing Jiaotong University

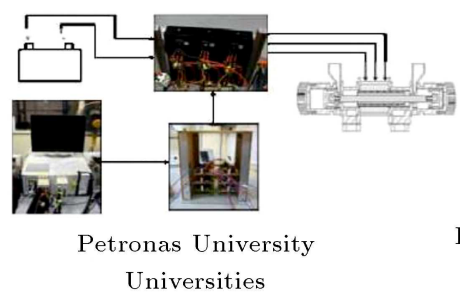

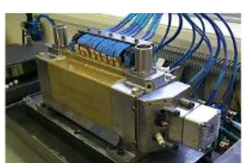

PEMPEK

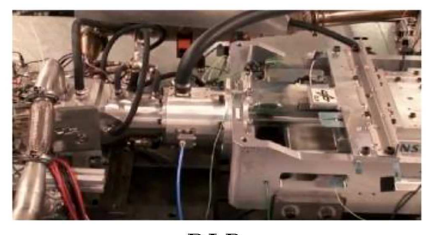

DLR

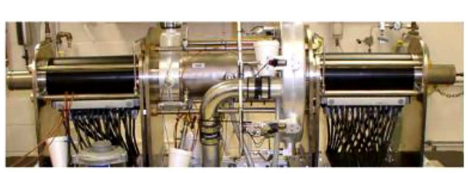

SANDIA

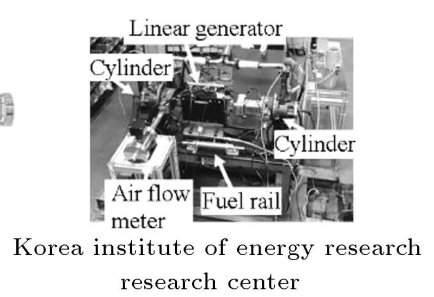

research center

Figure 2. Free piston engine studies.

University of Technology and Korea Institute of Energy Research $[7,8]$. The Czech Technical University has also developed a dual piston FPLG. The prototype properties include an operating frequency of $27 \mathrm{~Hz}$ and an electrical output power of approximately $350 \mathrm{~W}$ [9]. The Volvo Technology Center has previously conducted research on the differences between opposed piston FPLG and dual piston FPLG configurations before deciding to concentrate on the former [10]. A dual piston FPLG was designed by Pempek Systems as a two-stroke diesel [11]. An opposed piston engine with a flat-type linear alternator was successfully developed by Germany's National Research Center [12]. The Toyota Central Laboratory has successfully realized the design and application of a FPLG which uses resonant pendulum control [13,14]. Although some vehicle manufacturers have investigated the use of FPEs, they have yet to be deployed on a commercial basis. Beetron [15], Libertine [16], and Aquariusengines [17] are trying to develop commercial products that utilize FPE applications (Figure 2).

In FPEs, it is important to keep the mass of the moving part as low as possible due to kinematic considerations (in terms of increasing acceleration and mechanical frequency). Permanent Magnet (PM) flux switching machines have been investigated due to the ease with which they can be constructed [18]. Although transverse flux and induction linear machines have poor efficiency and produce a low power factor, they are simple and inexpensive [19].

Several studies have investigated various linear machine topologies for FPE applications, and PM Linear Generator (PMLG) designs are generally preferred due to their power and efficiency. In this study, the stator and moving parts were classed as primary and secondary, respectively. Figure 3 details the classification of this generator [20].

Tubular machines are classified as radial, axial, or Halbach, according to the direction of the magnetic flow. In slotless structures, the windings are lined in empty cylinders made of ferromagnetic material. In slotted structures, these windings are accommodated within slots, as suggested by their name. A slotted or slotless structure can be designed for one phase, three phase, or multiphase operation. Additionally, iron core machines provide higher force and stress when compared with air core machines. Therefore, they are more preferred in FPE designs. Table 1 contains general information from a survey of documented generator structures used in PFE systems.

In FPE application studies, PMs (50\% radial, $22 \%$ axial, and $14 \%$ Halbach) were preferred as the moving part in $86 \%$ of cases, while windings and cores were both preferred in $7 \%$ of evaluations. In terms of flux direction, $93 \%$ of the examples used a longitudinal design, while $7 \%$ employed a transverse configuration. 


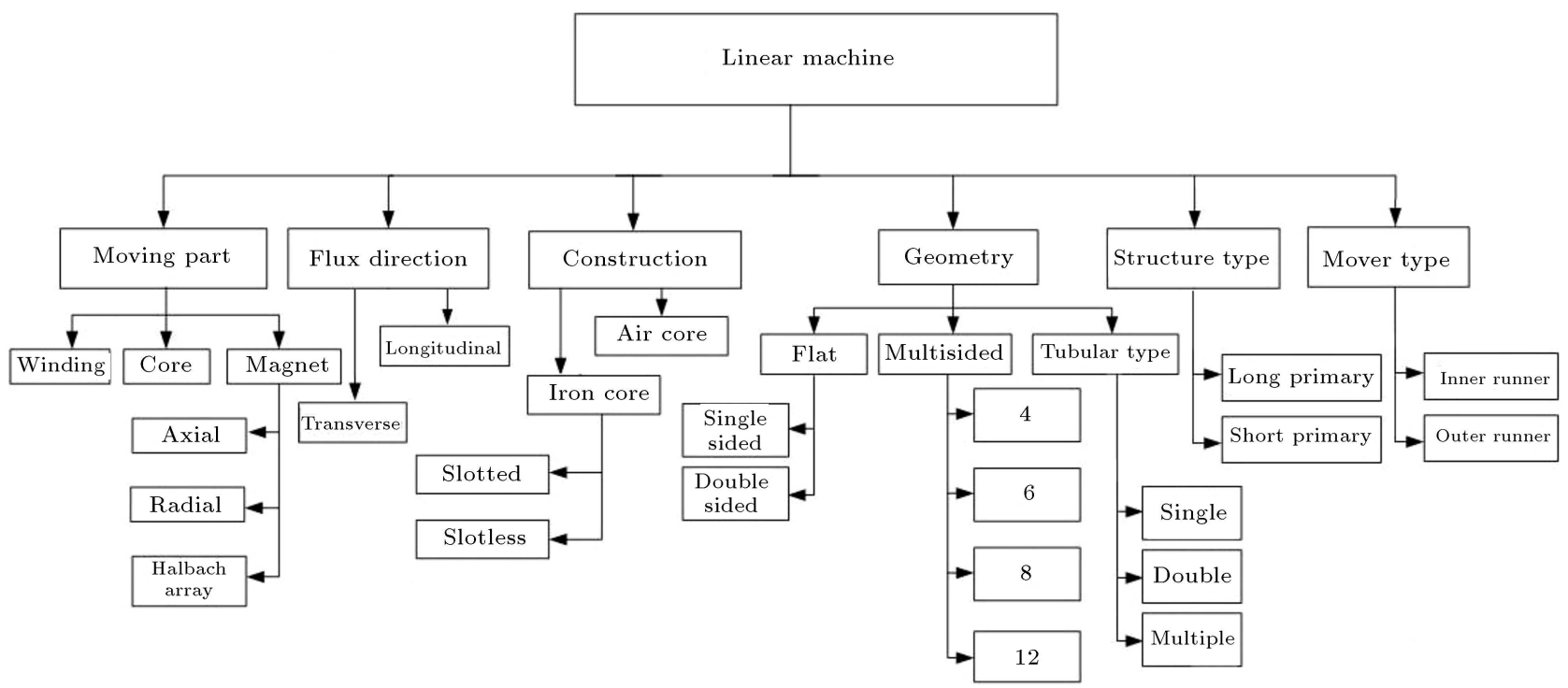

Figure 3. Linear machine classification.

Table 1. Survey of documented linear generator types in Free Piston Engine (FPE) systems.

\begin{tabular}{lccccc}
\hline Ref. no & Moving part $^{\text {a }}$ & Flux direction $^{\mathbf{b}}$ & Construction $^{\text {c }}$ & Structure type $^{\mathbf{d}}$ & Geometry $^{\mathbf{e}}$ \\
\hline$[38,39]$ & $\mathrm{Ma}$ & $\mathrm{L}$ & $\mathrm{Iy}$ & $\mathrm{SP}$ & $\mathrm{T}$ \\
{$[40]$} & $\mathrm{Ma}$ & $\mathrm{L}$ & $\mathrm{Iy}$ & $\mathrm{LP}$ & $\mathrm{T}$ \\
{$[41,43,44]$} & $\mathrm{Mr}$ & $\mathrm{L}$ & $\mathrm{Iy}$ & $\mathrm{SP}$ & $\mathrm{T}$ \\
{$[45,46]$} & $\mathrm{Mr}$ & $\mathrm{L}$ & $\mathrm{Iy}$ & $\mathrm{LP}$ & $\mathrm{T}$ \\
{$[47]$} & $\mathrm{Mr}$ & $\mathrm{L}$ & $\mathrm{Iy}$ & $\mathrm{LP}$ & $\mathrm{F}-\mathrm{DS}$ \\
{$[48]$} & $\mathrm{Mr}$ & $\mathrm{L}$ & $\mathrm{Iy}$ & $\mathrm{SP}$ & $\mathrm{F}-\mathrm{SS}$ \\
{$[42,49]$} & $\mathrm{Mh}$ & $\mathrm{L}$ & $\mathrm{Iy}$ & $\mathrm{T}$ & $\mathrm{T}$ \\
{$[50]$} & $\mathrm{C}$ & $\mathrm{T}$ & $\mathrm{Iy}$ & $\mathrm{SP}$ & $\mathrm{T}$ \\
\hline 51$]$ & $\mathrm{W}$ & $\mathrm{L}$ & $\mathrm{Ix}$ & $\mathrm{LP}$ & \\
\hline
\end{tabular}

${ }^{a}$ Moving Part $\rightarrow$ Ma: axially magnetized magnet; Mr: radially magnetized magnet; Mh: Halbach array;

$\mathrm{C}$ : core, $\mathrm{W}$ : winding.

${ }^{\mathrm{b}}$ Flux Direction $\rightarrow$ L: longitudinal, T: transverse.

${ }^{\mathrm{c}}$ Construction $\rightarrow \mathrm{A}$ : air core, I: iron core, $\mathrm{x}$ : slotless, $\mathrm{y}$ : slotted

${ }^{\mathrm{d}}$ Structure Type $\rightarrow$ LP: long primary, SP: short primary.

${ }^{\mathrm{e}}$ Geometry $\rightarrow$ T: tubular, F: flat, DS: double side, SS: single side.

Both slotted and slotless forms of construction were used. In terms of structure type, $64 \%$ had short primary windings, while $36 \%$ utilized long primaries. In terms of geometry, $86 \%$ were tubular, $7 \%$ singlesided, and $7 \%$ double-sided.

Linear generators can be used in renewable energy systems that produce electricity from wind [21] (airfoil system), sun (stirling engine system), and wave (in Archimedes' wave swing system).

When compared with the secondary, the primary can be either short or long by comparison. Short primary machines provide a greater effective force and cogging force [22]. In this design, the magnets in the moving parts are left outside, with the finding that they do not contribute to the generation of force [23].
Although the force/cost rate of long primary slotted or slotless radial and axial flux tubular machines is higher than that of short primary machines, force intensity and efficiency are reduced [24,25]. Thus, machines with a long primary are generally not preferred.

Tubular structures are characterized by the benefits of producing less leakage flux and higher electromagnetic forces and symmetric forces, thereby increasing the life of the bearings by reducing wear $[26,27]$. The use of single-sided flat-type machine forces is generally avoided since they are asymmetric $[28,29]$. While the magnetic flux intensity within the air gap of tubular generators is constant, multi-sided machines employ longer airways, e.g., the tetragon [30] and dodecagon [31], with the result that the intensity 
of the magnetic flow changes. When compared with the tubular generator, iron and copper losses are greater in tetragonal structures, thereby producing lower efficiency [30]. Tubular linear interior PM machine dimensions were optimally determined by genetic algorithm and sequential nonlinear programming [31]. In other works [32-34], analytical and numerical designs of tubular linear machine were presented for which a dynamic tool was developed using MATLAB and ANSYS and the performance improvement of an PMLG was achieved using optimization methods.

Axial flux machines can be converted into linear machines and analyzed using quasi 3D modeling and 3D modeling [35]. In this respect, the software method applied in this study can also be adopted for the analysis of axial flux machines.

This study was concerned with the design and application of the proposed multi-sided tube type linear alternator for hybrid vehicles. Geometric data for the generator was analytically calculated using the MATLAB GUI and ANSYS Maxwell 3D; Visual Basic code was converted into MATLAB program instructions. Communication between the MATLAB GUI and ANSYS Maxwell software allows the geometry to be automatically generated in the direction of the calculated data via the MATLAB GUI, and the numerical analyses of the generator are performed using the ANSYS Maxwell package. Based on the sizing data obtained, a tube-type alternator prototype was produced. Generator performance tests were carried out by establishing a slider crank mechanism with a similar speed profile to that of the free piston operating mechanism.

This paper is organized as follows: Section 2 outlines the design and structure of the PM Tubular Linear Generator (PMTLG) and user interface. Section 3 describes the theoretical modeling, finite element analysis, test setup, and experimental results obtained for the prototype.

\section{Design and structure of the PMTLG}

In order to provide a finite-element solution for a tubular linear generator, research was conducted on existing software packages. Unfortunately, no ready design tools exist for nontraditional generator topologies in which the analytical and Finite Element Methods (FEMs) can work together and unlike other studies, the design interface has been formed using the MATLABGUI. Flowchart of the design interface is given in Figure 4.

ANSYS Maxwell program, which could work dynamically with Visual Basic Script and Phython languages, was chosen for the development of the finite elements. The Visual Basic code of the rudimentary model, formed in ANSYS Maxwell, was designed within the MATLAB GUI (Figure 5).

In order to size the linear electric machines, it is vital to formulate the variables for force and velocity. Basic analytical equations for these parameters are given in Eqs. (1)-(13). The design of traditional rotary engines or generators begins with power expression.

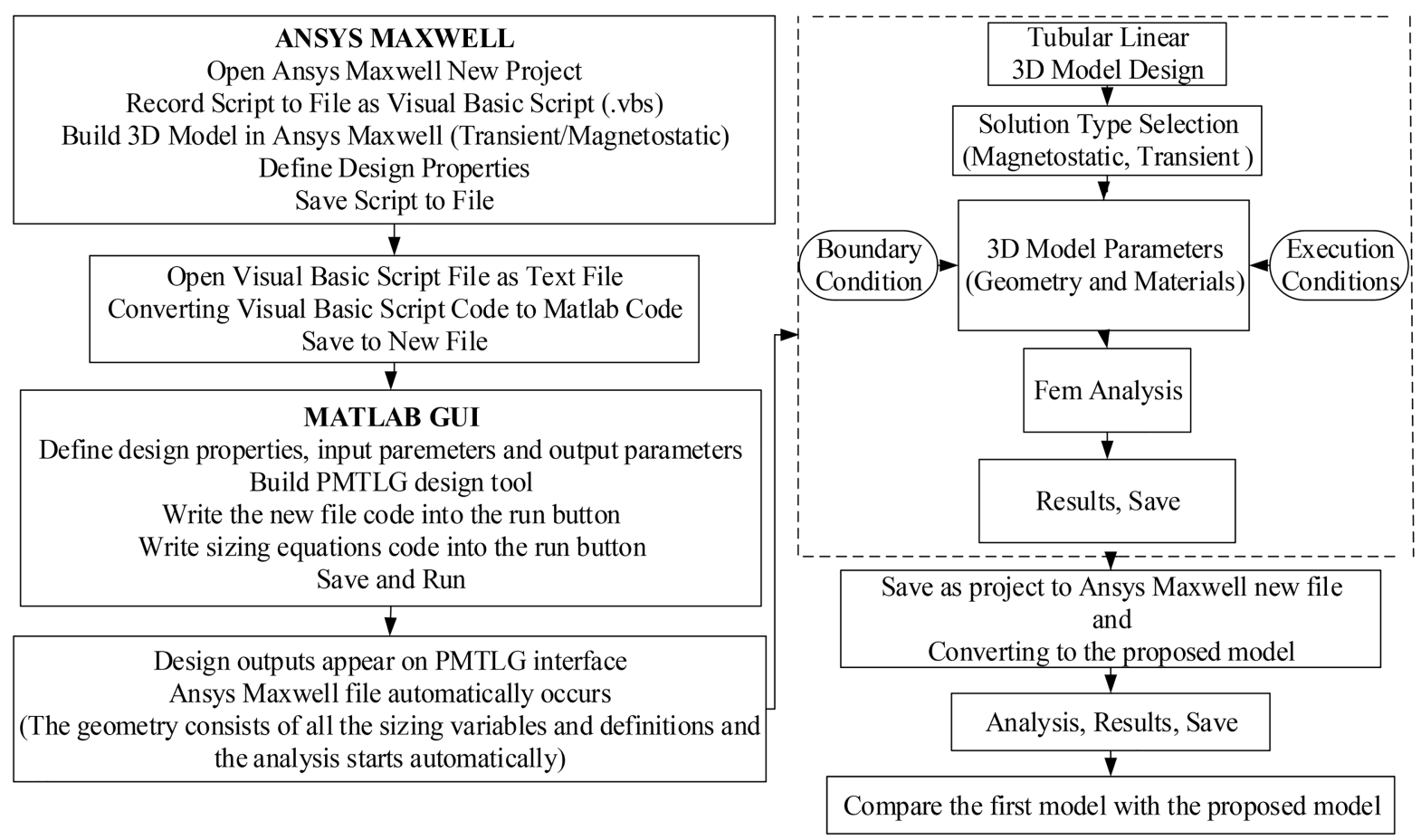

Figure 4. Flowchart of the design interface. 


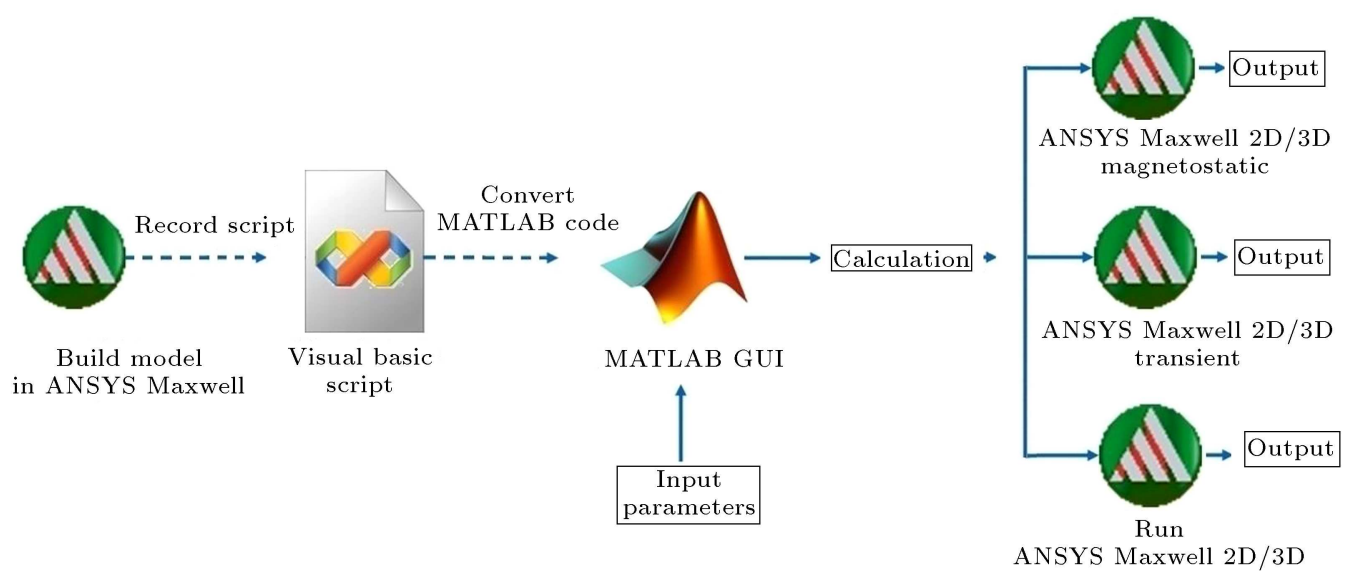

Figure 5. The process of forming code and the process of obtaining analytical and numerical data.

However, linear machines are characterized by force. Eqs. (1) and (2) give the velocity and force of the machine $[31-34,36]$, where $v, f, T_{o p}, F_{z}, P$, and $\eta$ are velocity $(\mathrm{m} / \mathrm{s})$, frequency $(\mathrm{Hz})$, pole pitch $(\mathrm{m})$, moving force in the $\mathrm{z}$ direction $(\mathrm{N})$, power (VA), and estimated efficiency, respectively.

$$
\begin{aligned}
& v=2 f T_{o p}, \\
& F_{z}=\frac{P}{\nu \eta}, \\
& L_{p}=T_{o p} N_{p},
\end{aligned}
$$

where $L_{p}$ is the length of the primary $(\mathrm{m}), N_{p}$ is the number of poles, $D$ is the inside diameter of the primary $(\mathrm{m})$, and $f_{d}$ is the share stress $\left(\mathrm{N} / \mathrm{m}^{2}\right)$.

The power expression of conventional rotary motors or generators is proportional to the square of the machine diameter and the product of the packet length $\left(D^{2} L\right)$. For linear generators, the overall size of the generator can be calculated with linear generator power density $\left(10000-30000 \mathrm{~N} / \mathrm{m}^{2}\right)$ and force.

$$
\begin{aligned}
& D=\frac{F_{z}}{\pi f_{d} L_{p}}, \\
& T_{o s}=\frac{T_{o p} N_{p}}{X_{s}}, \\
& L_{s}=L_{p}+2 L_{s t r},
\end{aligned}
$$

where $L_{s t r}$ is the length of the stroke $(\mathrm{m}), L_{s}$ is the length of the secondary $(\mathrm{m}), T_{o s}$ is the slot pitch $(\mathrm{m})$, and $X_{s}$ is the number of slots. Values of slot pitch ratio $(\beta)$ are selected between 0.4 and 0.6 , while a pole pitch ratio $(\alpha)$ between 0.5 and 0.8 is chosen. Width of teeth $\left(B_{w}\right)$ and width of magnets $\left(T_{m}\right)$ are expressed in Eqs. (7) and (8):

$$
\begin{aligned}
& B_{w}=\beta T_{o s}, \\
& T_{m}=\alpha T_{o p}, \\
& D=2 H_{s}+2 L_{m}+2 g, \\
& R_{f}=\rho \pi\left(D+H_{p 0}+H_{p 1}+H_{p w}\right) \frac{X_{s}}{3} \frac{N_{f} j}{I_{f}}, \\
& P_{i}=F_{z} \nu \\
& P_{o}=3 E_{f} I_{f}, \\
& \eta=\frac{P_{o}}{P_{i}}
\end{aligned}
$$

where $D$ is the stator bore diameter of the machine (m), $H_{s}$ the secondary steel radius of the machine $(\mathrm{m})$, $L_{m}$ the height of magnets $(\mathrm{m}), g$ the air-gap length (m), $\rho$ the electrical resistivity of copper $(\Omega \mathrm{m}), R_{f}$ the resistance of phase $(\Omega), I_{f}$ the current of phase, $j$ the copper current density, $N_{f}$ number of turns per phase, $H_{p 0}$ the open hollow height, $H_{p 1}$ the maximum hollow stud height, $H_{p w}$ the coil height, $P_{i}$ the input power of the machine (VA), $P_{o}$ the output power of the machine (VA), $E_{f}$ the induced voltage of phase windings, and $\eta$ the efficiency.

The basic geometrical data of the machine were obtained using the analytical sizing equations defined in the MATLAB GUI. ANSYS Maxwell defined within MATLAB GUI was formed automatically on linear generator ANSYS-Maxwell 2D- $r z$ plane and ANSYS Maxwell 3D according to the sizing data obtained using different operating tools (transient, magnetostatics, optimization, etc.) and analyses were conducted then. Figure 6 illustrates the 2D sizing of the tubular linear generator $[33,34]$. 


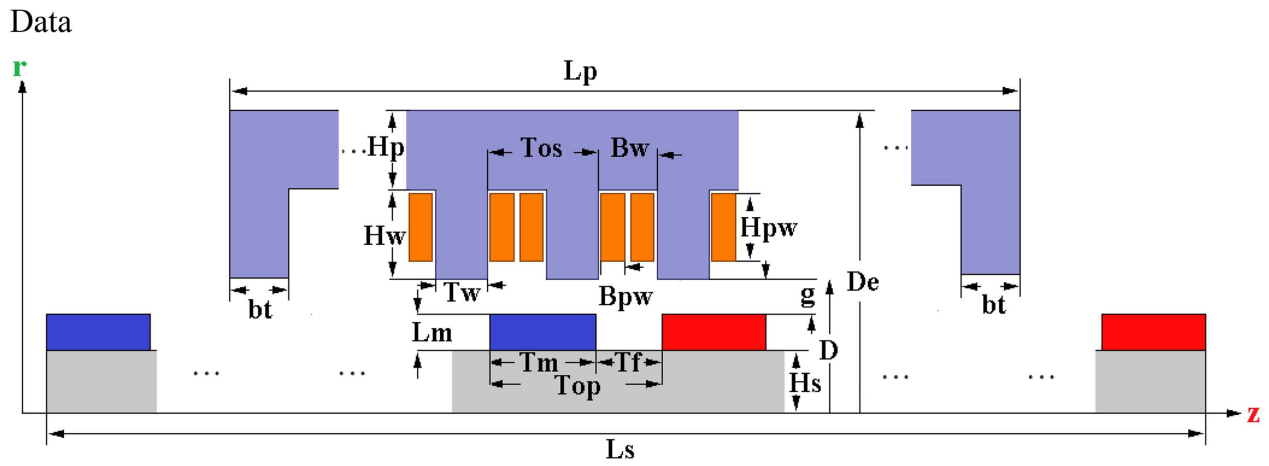

Figure 6. 2D $r z$ plane sizing of the tubular linear generator.

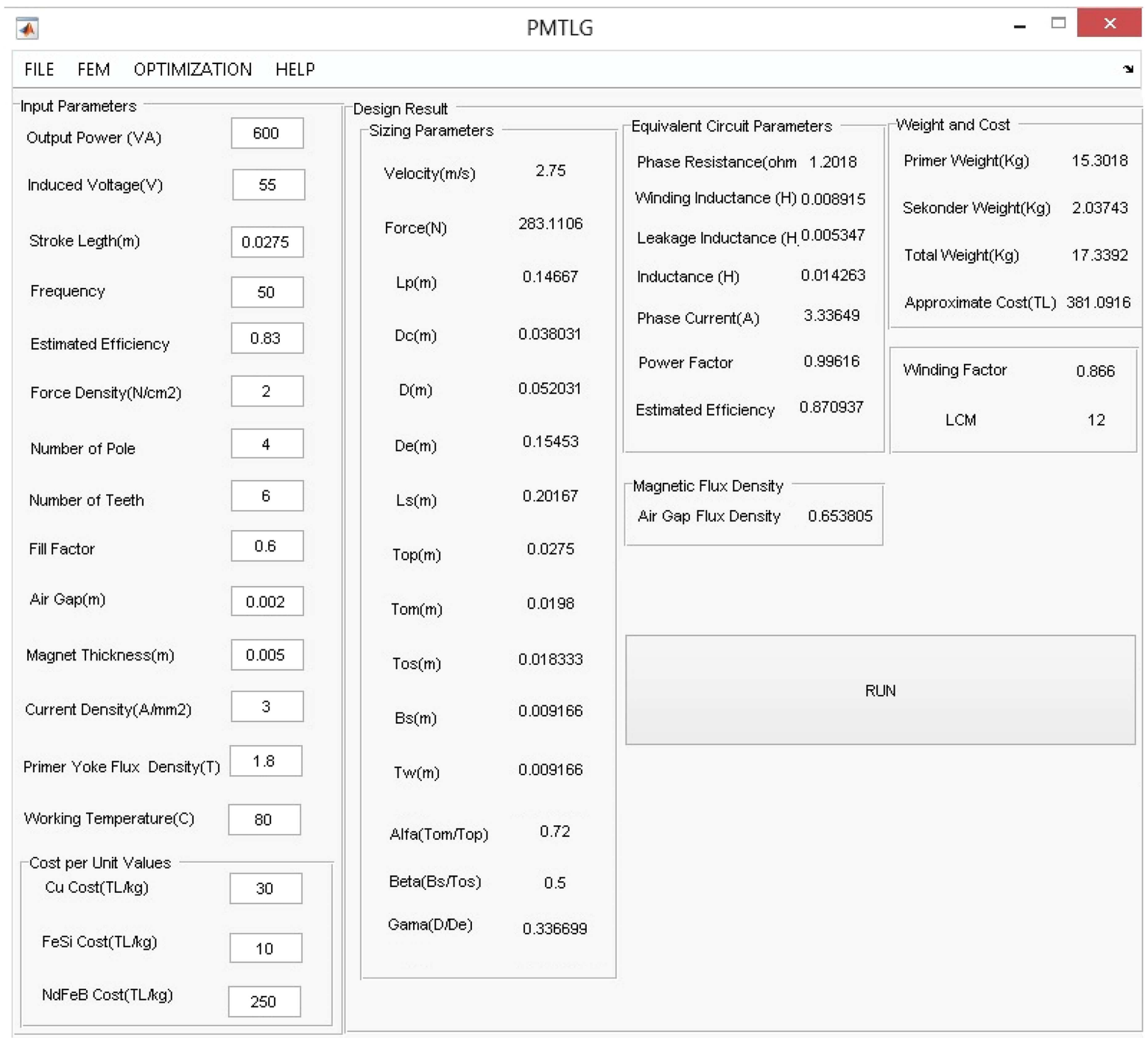

Figure 7. PM Tabular Linear Generator (PMTLG) - Main sheet showing input parameter, design result, and electrical parameter in the MATLAB GUI interface.

Design sizes given in Figure 6 were calculated on the basis of the input parameters in the design interface, shown in Figure 7. The heart of the PMTLG design process is the analytical method and finite element based solver, and these two components work together to allow suitable modeling. The use of this software does not require any particular expertise and navigation is aided by the inclusion of the GUI. Figure 7 shows the main sheets for the PMTLG program that was developed. 


\section{Examination of analysis and application results for tubular alternator}

While the linear machine has a 3D geometry, it is easy to convert this into a $2 \mathrm{D}$ geometry for the purpose of modeling. The conventional tube-type machine and the recommended one are detailed in Figure 8.

The traditional model in Figure 8 is the primary (stator) single part. The moving part (secondary) consists of ring magnets placed on the steel. The stator of the proposed model is dodecagon shape and the secondary is made of block magnets placed on steel. If the stator is like a $3 \mathrm{D}$ solid model, the lamination fill factor is considered $100 \%$. The circumference of the stator inner bore of the $3 \mathrm{D}$ solid and proposed

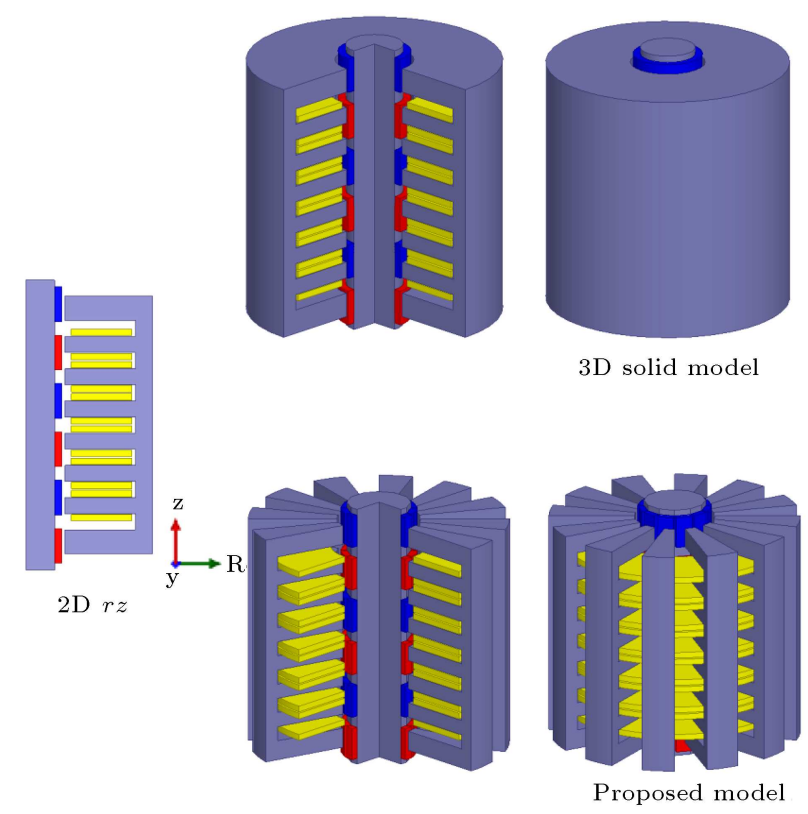

Figure 8. Finite Element Analysis (FEA) model of tubular linear generator; the traditional surface permanent and proposed structure. models (i.e., $\pi D$ ) is equal to $163.36 \mathrm{~mm}$ and $120 \mathrm{~mm}$, respectively. In the case of the proposed model, it was found that the ratio of the total lamination material to the total stator area available was $73.45 \%$.

The application of 2D FEM to electrical machine design facilitates determining important parameters such as flux density, winding inductances, and electromagnetic force with high levels of accuracy. The use of this method provides cost and time savings during the analysis of the machine. It is firstly necessary to choose the required dimensions for the machine geometry, which is formed in accordance with the calculated geometry data. Among the model parameters, the threshold conditions are introduced; in the analysis of magnetic problems, vectors are potentially considered zero. During propulsion conditions, the number of windings and in the case of motor operation, rated current or rated voltage are specified. During operation as a generator, the rated speed value is given.

A magnetostatic analysis simulator is used to facilitate the application of static magnetic fields (direct current or PM). Analytical and numerical methods are preferred for the calculation of generator/motor inductance. The analytical methods assume the following: (a) The magnetic flux density-magnetic field strength $(B-H)$ curves of magnetic materials change linearly (the saturation effect is not taken into consideration), (b) The cogging force does not exist, and (c) Provision for simplified primary and secondary structures, i.e., taken as the idealized machine winding distribution. Although calculations using analytical methods give close results, flux distribution can be seen in magnetic field analysis conducted through FEM (Figures 9 and $10)$.

When the translator moves, the eddy current loss is generated in the PMs. The eddy current loss of the translator in the no-load mode results from the effect of the slot opening [37]. 3D FEM Analysis is carried

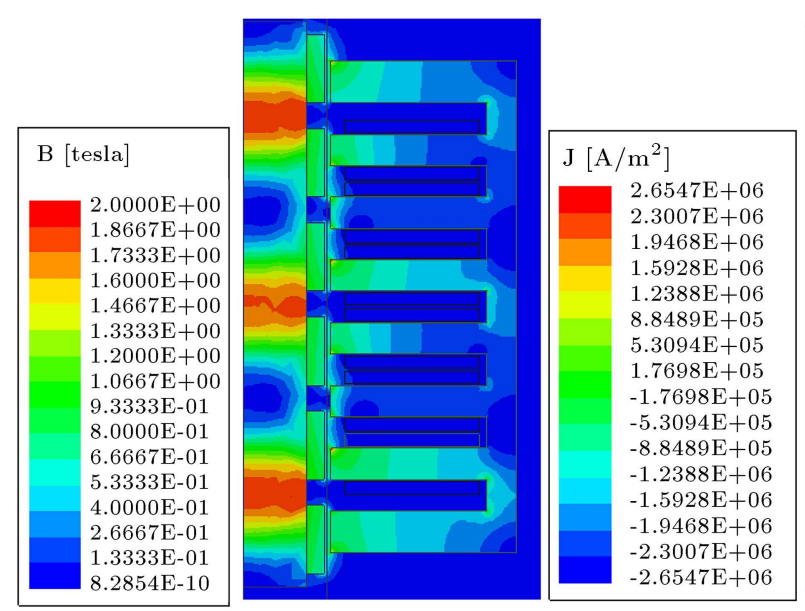

(a)

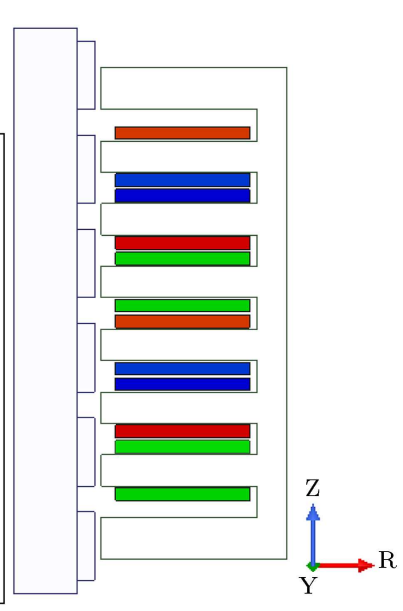

(b)

Figure 9. (a) 2D model magnetic field distributions. (b) 2D model current density distributions. 

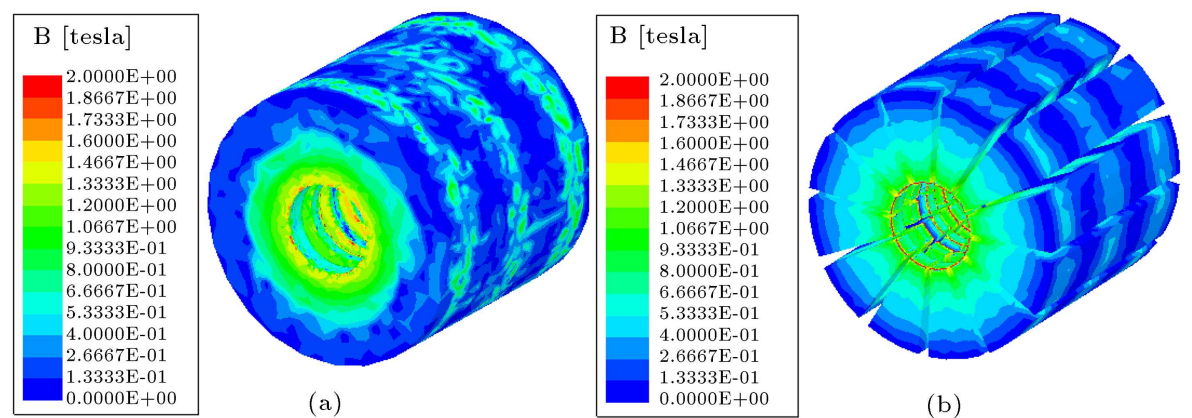

(b)

Figure 10. (a) Solid model magnetic field distributions. (b) Slitted model magnetic field distributions.
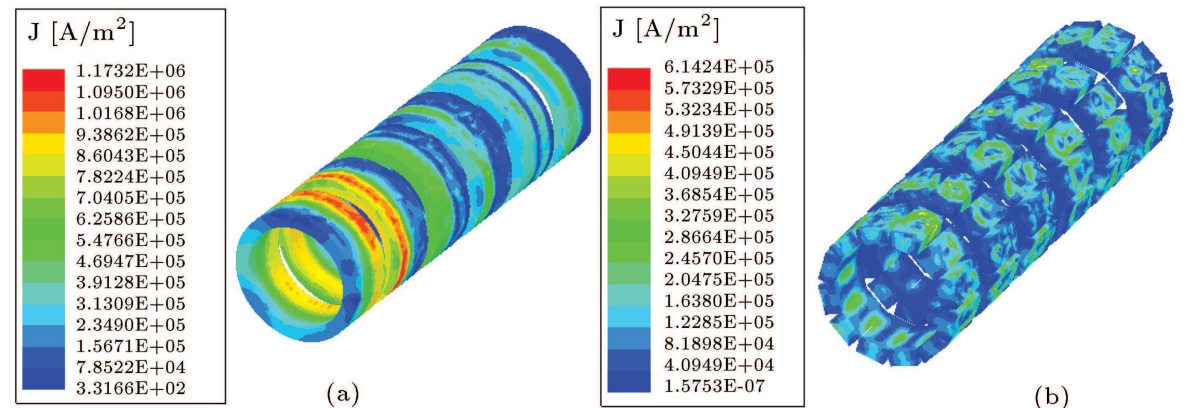

Figure 11. (a) Eddy current distribution of ring-shaped magnets in the solid model. (b) Eddy current distribution of the segmented magnets in the slitted model.

out on the two models to evaluate the magnet eddycurrent losses. As shown in Figure 11(b), a new kind of structure is put forward using multiple pieces of PM instead of the conventional single piece in Figure 11(a). The machines are running at a speed of $5.5 \mathrm{~m} / \mathrm{s}$. Figure 11 presents the eddy current density generated by the translator at a time of $1.7 \mathrm{~ms}$.

As is known earlier, magnet segmenting is one of the effective ways to reduce the magnet eddy current loss. As can be observed, the PM eddy current loss is reduced significantly with the segmented magnets in Figure 11.

Temporal analyses were conducted to assess the effects of functionally stated flows and voltages on magnetic systems. In this context, these investigations were carried out until the generator/motor working state would become stable. Based on the speed change, the simulation results for the voltage induced by the phase winding were examined. By using Ansys Maxwell, the voltage-time change induced through the winding for the simulation under no load is shown in Figure 12. Its maximum value is $72 \mathrm{~V}, 101.7 \mathrm{~V}$, $77.46 \mathrm{~V}, 96.93 \mathrm{~V}$ in one-phase stator winding in the cases of application, 2D $r z$ FEM, proposed model, and solid model, respectively.

The voltage change induced by the models is given here. Two-dimensional and three-dimensional traditional model structures are similar to each other. The error rate was found to be $-4.9 \%$. The error

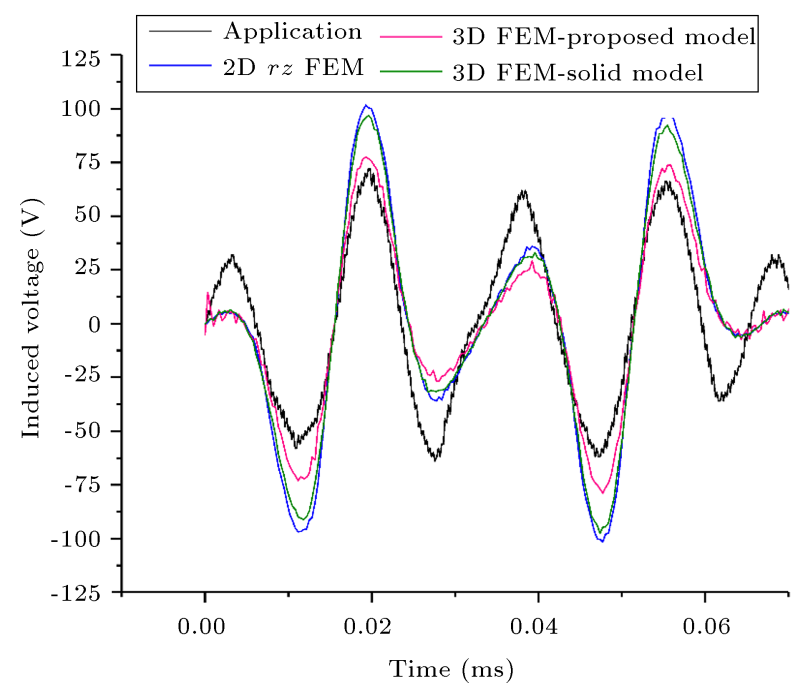

Figure 12. The induced voltage in the no-load condition in one-phase stator winding.

between the application and the three-dimensional proposed model was calculated as $-7.5 \%$. Besides, the comparison between the analytical calculation results and FEM results is given in Table 2.

Good agreement was obtained between the analytical results and FEM predictions. All analyses were performed using computers featuring i7-6700 CPU, $3.7 \mathrm{GHz}, 16 \mathrm{~GB}$ RAM. The mesh numbers and solution time of each analysis are given in Table 3 . 
Table 2. The comparison between the analytical calculation results and Finite Element Method (FEM) results.

\begin{tabular}{ccc}
\hline Parameters & $\begin{array}{c}\text { MATLAB GUI Analytical } \\
\text { calculation results }\end{array}$ & $\begin{array}{c}\text { ANSYS Maxwell 2D } \boldsymbol{r} \boldsymbol{z} \\
\text { FEM results }\end{array}$ \\
\hline Efficiency & 0.8709 & 0.813 \\
Air gap flux density (T) & 0.653 & 0.572 \\
Phase current (A) & 3.33 & 3.11 \\
Inductance (mH) & 14.26 & 13.61 \\
\hline
\end{tabular}

Table 3. The number of $2 \mathrm{D}$ and $3 \mathrm{D}$ meshes and solution time.

\begin{tabular}{ccc}
\hline Models & Total number of elements & Solution CPU time \\
\hline 2D rz Model & 16886 & $17 \mathrm{~min}$ \\
3D solid (reference) & 37259 & $3 \mathrm{hr} 23 \mathrm{~min}$ \\
3D proposed model & 38106 & $2 \mathrm{hr} 06 \mathrm{~min}$ \\
\hline
\end{tabular}

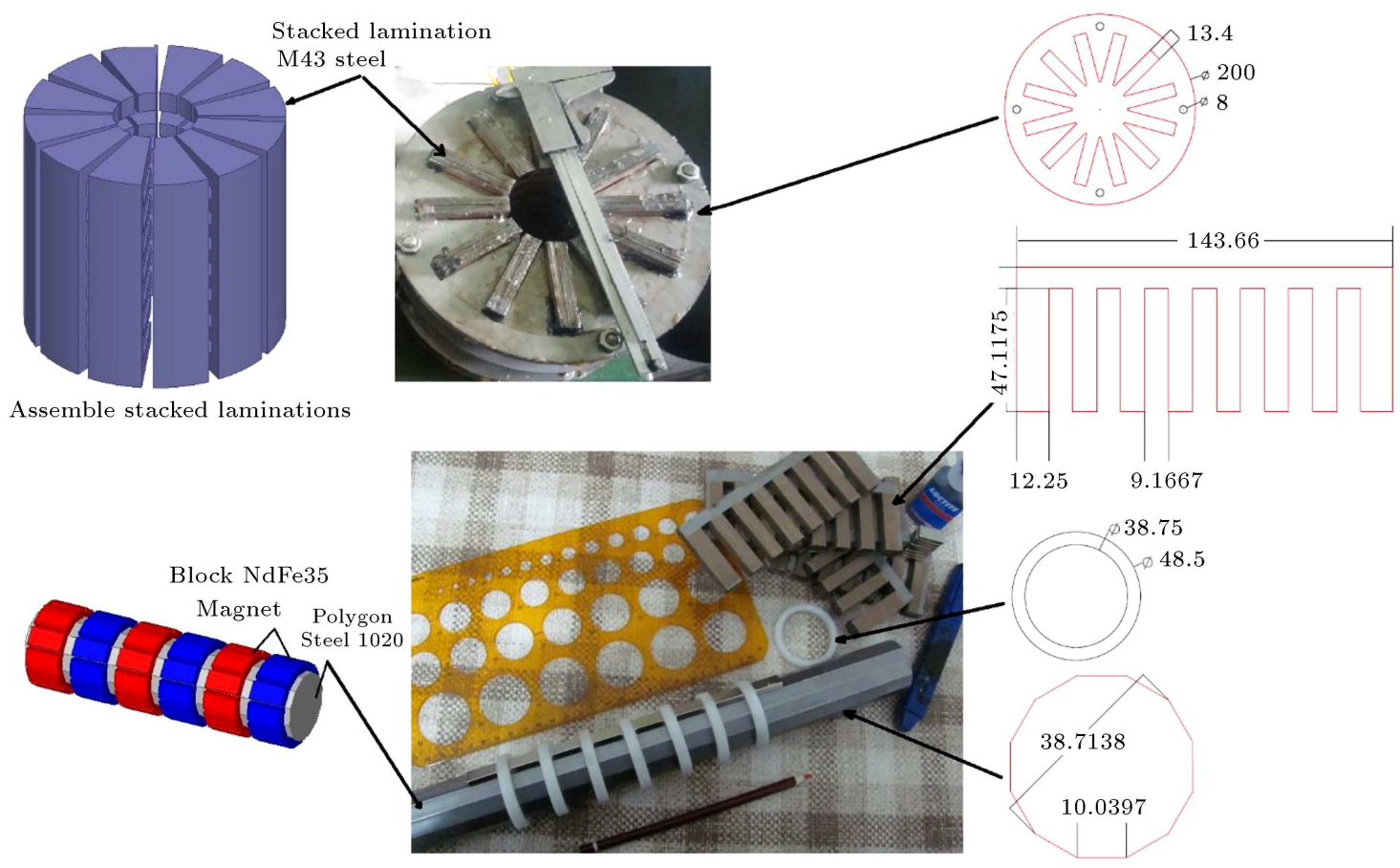

Figure 13. Manufactured core, secondary steel, and polyimide ring.

\subsection{Proposed design manufacturing process}

The PMTLG interface determines the quality of the analytical design results and mathematical calculations. However, the design is essentially untried until it has been applied. Figure 13 contains pictures of the materials used for the production of the primary and secondary.

A M43-26G laminated steel core was used in the primary and this was produced using the laser cut method and manufactured to provide longitudinal flux. It is possible to use Somaloy or Soft Magnetic Composites (SMC) instead of laminated steel core; however, these materials were not preferred for this study due to their iron loss properties, low magnetic flux density, and manufacturing costs. The block magnets in the secondary consisted of 1020 steel, which is dodecagon. Since polygonal shapes cannot be made with a turning machine, this material was manufactured using a Computer Numerical Control (CNC) machine. Titanium pipe, with an outer diameter of $51 \mathrm{~mm}$, was used in order to protect the primary cogs of the magnets, which are placed on the moving secondary structure, from unwanted side effects, such as friction and erosion. The total weight of the secondary was calculated as $2.65 \mathrm{~kg}$, and chrome material was preferred for the outer body design. Side lids were manufactured using the process of bending and welding. Figure 14(a) shows the windings and primary in situ. In addition, an LCR 


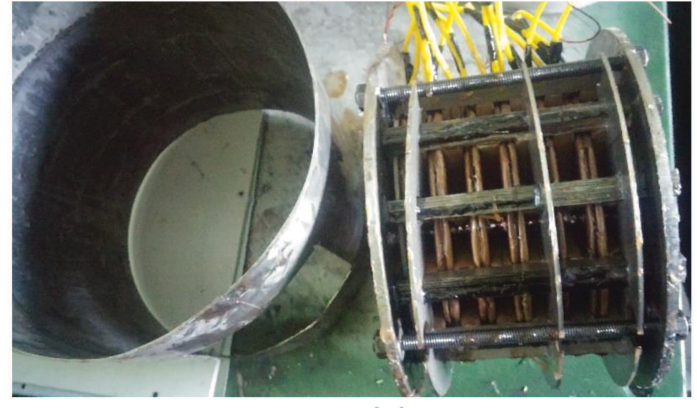

(a)

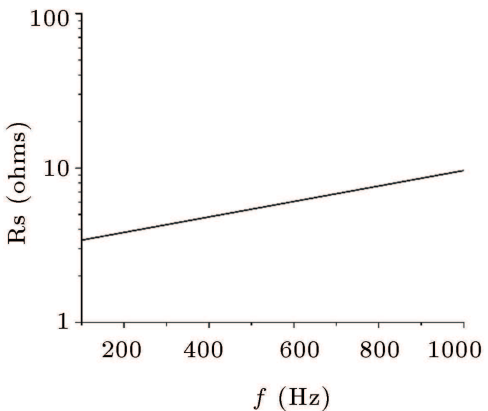

(b)

Figure 14. (a) View of tubular generator primary with two-layer ring coil. (b) Phase winding measured by LCR meter.

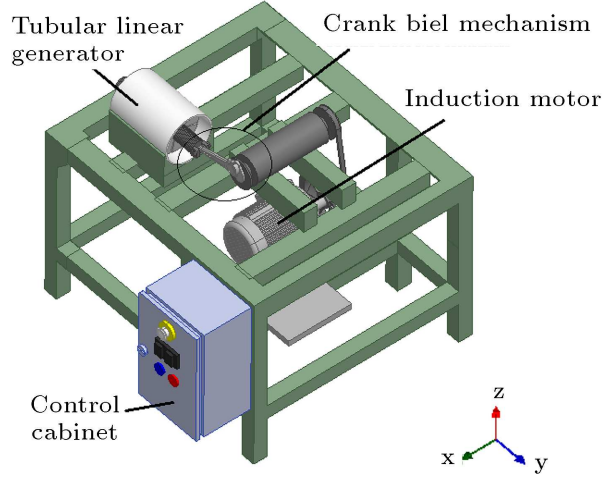

(a)

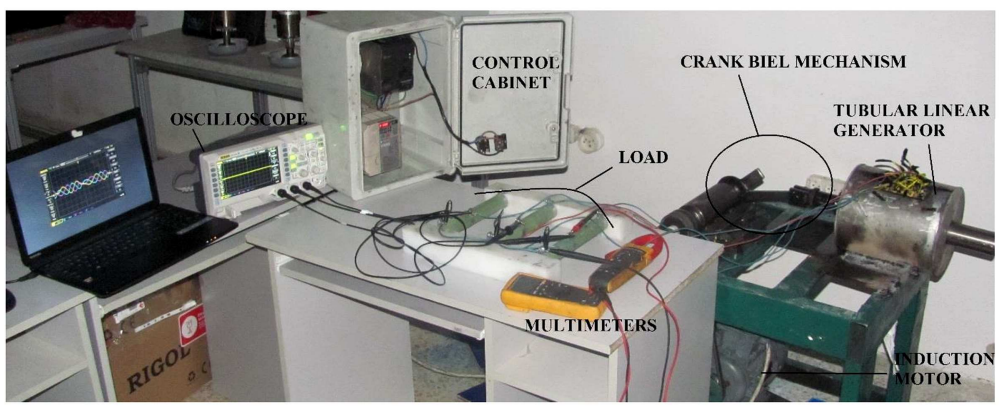

(b)

Figure 15. (a) Schematic of the integrated design of the PMTLG-based crank slider unit. (b) Picture of the prototype machine and test bench.

meter was used and subsequent calculations were made to determine the winding parameters of the generators (Figure 14(b)).

\subsection{Tubular linear experimental studies}

In free piston applications, the speed profile is sinusoidal in form and it is necessary to design a crank mechanism that can provide this characteristic. An asynchronous motor was used to wind up the system, and a driver was employed to ensure that the shaft speed of this motor could be changed in various frequency steps. Mechanical energy from the asynchronous motor shaft was transmitted through a mechanical slide ring system. Crank arm length was taken as $200 \mathrm{~mm}$ and the radius was taken as $35 \mathrm{~mm}$; thus, a stroke length of $\pm 35 \mathrm{~mm}$ was achieved. Figure 15 illustrates the appearance of the mechanical system [32].

Using the experimental test configuration shown in Figure 15, during measurements conducted with a turn meter when the generator was under no-load conditions, the rotational speed of the crank was recorded at approximately $550 \mathrm{rpm}$ and $1100 \mathrm{rpm}$ at drive frequencies of $10 \mathrm{~Hz}$ and $20 \mathrm{~Hz}$, respectively. The voltage waveforms induced at the phase winding of the three-phase generator for no-load operating states at
$10 \mathrm{~Hz}$ and $20 \mathrm{~Hz}$ are shown in Figures 16 and 17, respectively.

The generator was operated at different load values ranging from $5 \Omega$ to $50 \Omega$ at drive frequencies of $10 \mathrm{~Hz}$ and $20 \mathrm{~Hz}$ and experimental measurement data were obtained (Figure 18).

A rise in load voltage with an increase in load at constant frequency is an expected finding. The mechanical frequency of the designed generator is $50 \mathrm{~Hz}$, and since the linear driven mechanical system works as a single piston motor, it creates very high vibrations. Welded components are unable to withstand high levels of mechanical vibration and for these reasons, the required rated speed value was not reached. Thus, measurements were confined to drive frequencies of $10 \mathrm{~Hz}$ and $20 \mathrm{~Hz}$. The generator produces a different power at each load point for every frequency based on the secondary moving speed. As the mechanical frequency changes, the winding impedance of the generator is also altered. Thus, the change in load values at different mechanical frequencies is an expected outcome.

\section{Conclusion}

In this study, analytical measurements of a tubular linear generator model were conducted using a MATLAB 


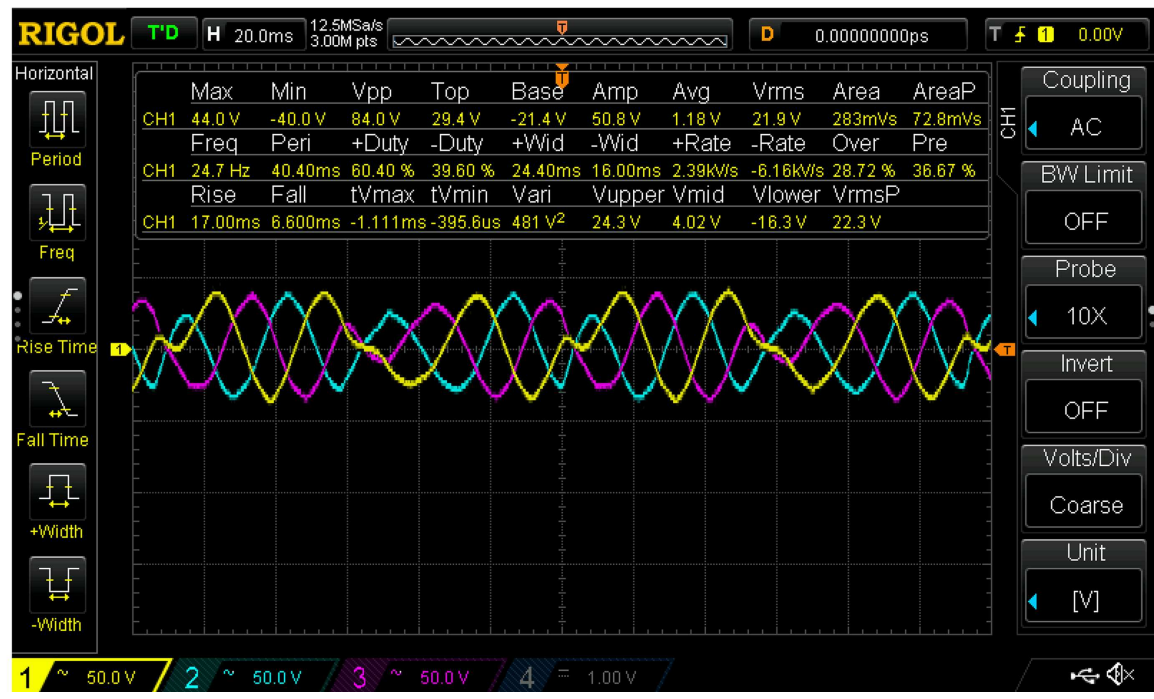

Figure 16. Output voltage of no-load three phase generator $(10 \mathrm{~Hz})$.

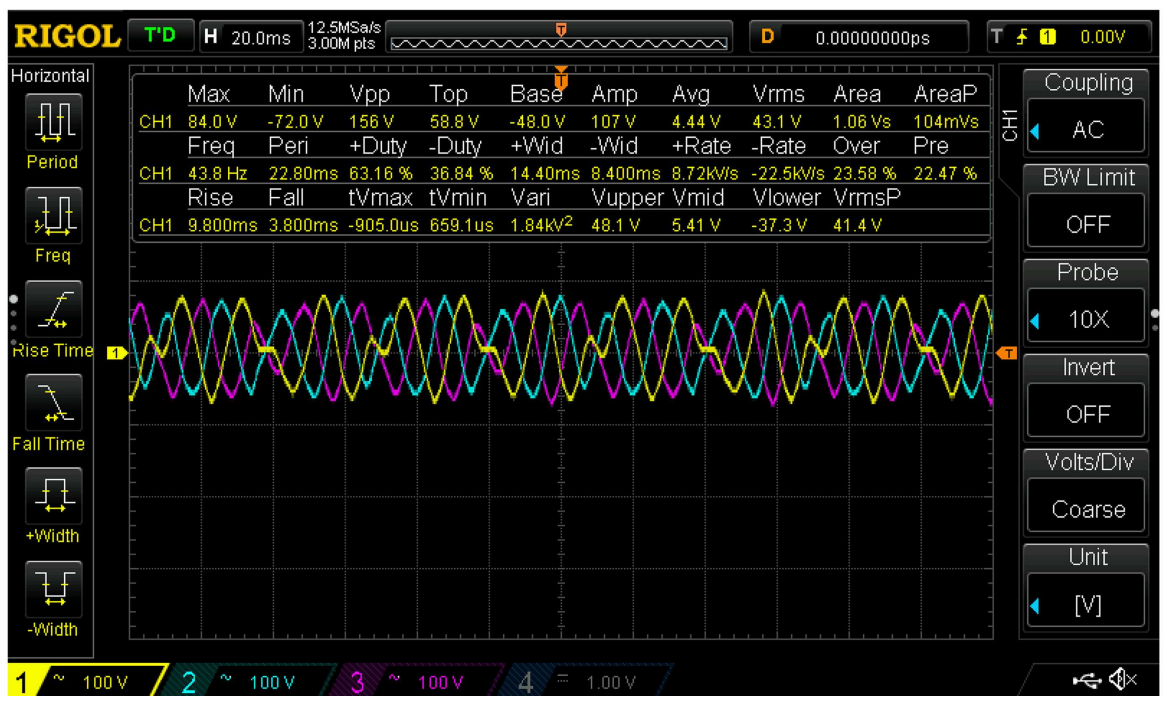

Figure 17. Output voltage of no-load three phase generator $(20 \mathrm{~Hz})$.

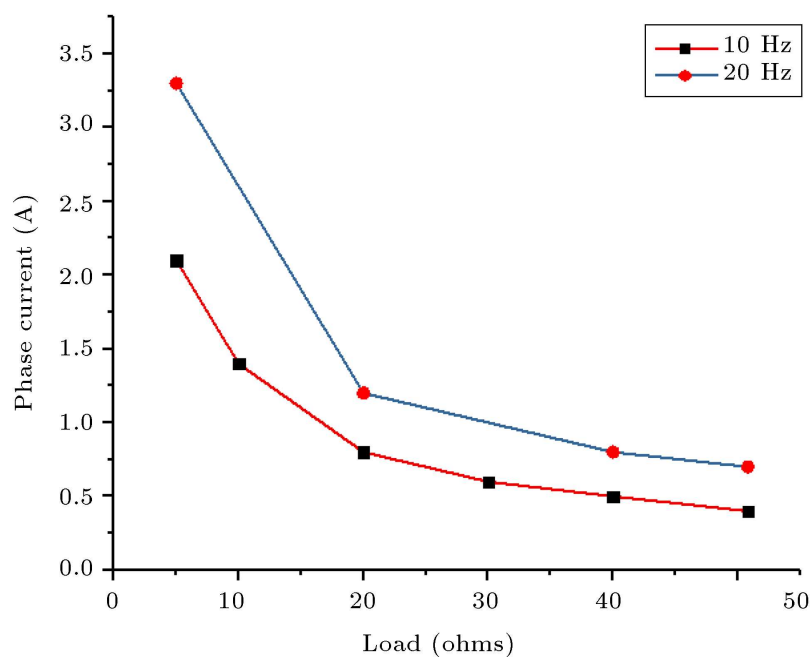

Figure 18. The phase current of the machine versus electrical load.
GUI for free piston applications. Data was automatically transferred via the tabs of the MATLAB GUI interface to the ANSYS -Maxwell 2D- $r z$ plane in order to carry out various analyses using the finite elements model. Details of the ANSYS Maxwell Visual Basic script code transformation are given in the Appendix to this document.

This study successfully realized the design and application of an internal combustion free piston generator in the absence of any ready commercial interface software. A balance weight was not used in the crank rod mechanism and it was, therefore, not possible to work at higher drive frequencies. However, it is expected that the induced voltage and power will increase as a function of a rise in frequency. It is considered likely that the effects of vibration be reduced through the application of a balancing piston configuration in this nontraditional generator design. 
Future studies will examine the thrust and control characteristics when this prototype generator is used as a motor throughout the Free Piston Engine (FPE) starting process.

\section{References}

1. Aichlmayr, H.T. "Design considerations, modeling, and analysis of micro-homogeneous charge compression ignition combustion free-piston engines", $\mathrm{PhD}$ Thesis, Minnesota, USA (2002).

2. Mikalsen, R. and Roskilly, A.P. "A review of freepiston engine history and applications", Applied Thermal Engineering, 27(14), pp. 2339-2352 (2007).

3. Cawthorne, W.R., Famouri, P., Chen, J., et al. "Development of a linear alternator-engine for hybrid electric vehicle applications", IEEE Transactions on Vehicular Technology, 48(6), pp. 1797-1802 (1999).

4. Houdyschell, D. "A diesel two-stroke linear engine", Master Thesis, West Virginia, USA (2000).

5. Blarigan, V.P., Paradiso, N., and Goldsborough, S. "Homogeneous charge compression ignition with a free piston: a new approach to ideal otto cycle performance", SAE Technical Paper, Series 982484, pp. 89106 (1998).

6. Blarigan, P.V. "Advanced internal combustion electrical generator", Proceedings of the 2002 U.S. Hydrogen Program Review, Colorado (2002).

7. Abidin, E.Z.Z., Ibrahim, A.A., Aziz, A.R.A., et al. "Investigation of starting behaviour of a free-piston linear generator", Journal of Applied Sciences, 12(24), pp. 2592-2597 (2012).

8. Woo, Y., Lee, Y., and Lee, Y. "The performance characteristics of a hydrogen-fuelled free piston internal combustion engine and linear generator system", International Journal of Low-Carbon Technologies, 4(1), pp. 36-41 (2009).

9. Nemecek, P. and Vysoky, O. "Control of two-stroke free-piston generator", In Proceeding of the 6th Asian Control Conference, Indonesia (2006).

10. Max, E. "FPEC, free piston energy converter", in Proc. of EVS 21, Monaco (2005).

11. Vysok, O. "Linear combustion engine as main energy unit for hybrid vehicles", Proceedings of Transtec Prague, Czech (2007).

12. Kock, F., Heron, A., Rinderknecht, F., et al. "Der FreikolbenLineargenerator Potenziale und Herausforderungen", MTZ - Motortechnische Zeitschrift, 74(10), pp. 774-779 (2013).

13. Kosaka, H., Akita, T., Moriya, K., et al. "Development of free piston engine linear generator system part 1 - investigation of fundamental characteristics", $S A E$ 2014 World Congress \& Exhibition, Michigan (2014).

14. Goto, S., Moriya, K., Kosaka, H., et al. "Development of free piston engine linear generator system part 2 - investigation of control system for generator", $S A E$ 2014 World Congress \& Exhibition, Michigan (2014).
15. "Free-piston power generator", [Online], Available: http://www.beetron.ch (2018).

16. "Free piston engine development", [Online], Available: http://www.libertine.co.uk (2019).

17. “Aquarius Engines' free-piston linear generator", [Online], Available: https://www.greencarcongress.com/ 2016/07/20160721-aquarius.html (2018).

18. Jiabin, W., Weiya, W., Atallah, K., et al. "Design considerations for tubular flux-switching permanent magnet machines", IEEE Transactions on Magnetics, 44(11) pp. 4026-4032 (2008).

19. Arshad, W.M., Thelin, P., Backstrom, T., et al. "Use of transverse-flux machines in a free-piston generator", IEEE Transactions on Industry Applications, 40(4), pp. 1092-1100 (2004).

20. Arslan, S., Gürdal, O., and Oy, A.S. "Communication of matlab gui and ansys maxwell: an education tool for tubular linear generator", J. Fundam. Appl. Sci., 11(1), pp. 117-141 (2019).

21. Darijani, H. and Panahi, A. "On a conceptual method for the extraction of wind energy using airfoil and linear generator", Scientia Iranica (B), 24(2), pp. 597609 (2017).

22. Youn, S.W., Lee, J.J., Yoon, H.S., et al. "A new cogging-free permanent-magnet linear motor", IEEE Transactions on Magnetics, 44(7), pp. 1785-1790 (2008).

23. Arshad, W.M., Backstrom, T., Thelin, P., et al. "Integrated free-piston generators: an overview", IEEE Norpie-02 Conference, Sweden (2002).

24. Bianchi, N., Bolognani, S., Corte, D.D., et al. "Tubular linear permanent magnet motors: an overall comparison", IEEE Transactions on Industry Applications, 39(2), pp. 466-475 (2003).

25. Arshad, W.M., Sadarangani, C., Backström, T., et al. "Finding an appropriate electrical machine for a free piston generator", 19th Electrical Vehicle Symposium (EVS), Korea (2002).

26. Jung, I.S., Yoon, S.B., Shim, J.H., et al. "Analysis of forces in a short primary type and a short secondary type permanent magnet linear synchronous motor", IEEE Transactions on Energy Conversion, 14(4), pp. 1265-1270 (1999).

27. Arof, H., Eid, A.M., and Nor, K.M. "Permanent magnet linear generator design using finite element method", ICEEC'04 International Conference In Electrical- Electronic and Computer Engineering, Cairo (2004).

28. Chen, A., Arshad, W.M., Thelin, P., et al. "Analysis and optimization of a longitudinal flux linear actuator for hybrid electric vehicle applications", IEEE Vehicle Power and Propulsion, Paris (2004).

29. Ribeiro, J. and Martins, I. "Development of a low speed linear generator for use in a wave energy converter", Renewable Energy \& Power Quality Journal, $\mathbf{1}(8)$, pp. 252-257 (2010). 
30. Oprea, C.A., Martis, C.S., Jurca, F.N., et al. "Permanent magnet linear generator for renewable energy applications: Tubular vs. four-sided structures", International Conference In Clean Electrical Power (ICCEP), Ischia (2011).

31. Arslan, S. and Oy, A.S. "Design and optimization of tube type interior permanent magnets generator for free piston applications", TEM Journal, 6(2), pp. 214221 (2017).

32. Arslan, S., Gurdal, O., and Akkaya Oy, S. "Design and optimization of tubular linear permanent-magnet generator with performance improvement using response surface methodology and multi-objective genetic algorithm", Scientia Iranica, 27(6), pp. 3053-3065 (2020).

33. Arslan, S., Gurdal, O., and Oy, A.S. "The determination of effects of primary and secondary geometry of tubular linear generator", IOSR Journal of Electrical and Electronics Engineering, 12(1), pp. 6-11 (2017).

34. Arslan, S. "Design and application of tubular type linear generator", PhD Thesis, Ankara, Turkey (2017).

35. Abbaszadeh, K. and Rahimi, A. "Analytical quasi 3D modeling of an axial flux PM motor with static eccentricity fault", Scientia Iranica, D, 22(6), pp. 2482-2491 (2015).

36. Boldea, I., Linear Electric Machines, Drives, and MAGLEVs Handbook, Boca Raton: CRC Press, pp. 1-660 (2013).

37. Abdalla, I.I., Ibrahim, T., and Nor, N.M. "Minimization of eddy-current loss in a permanent-magnet tubular linear motor", International Journal on Advanced Science, Engineering and Information Technology, 7(3), pp. 964-970 (2017).

38. Hong, S.K., Choi, H.Y., Lim, J.W., et al. "Analysis of tubular-type linear generator for free-piston engine", Renewable Energies and Power Quality Journal, 1(5), pp. 719-722 (2007).

39. Lim, J., Hong, S.K., and Jung, H.K. "Design and analysis of $5 \mathrm{kw}$ class tubular type linear generator for free-piston engine", International Journal of Applied Electromagnetics and Mechanics, 35(4), pp. 231-240 (2011).

40. Tatarnikov, A.P., Lezhnev, L.Y., Khripach, N.A., et al. "Two stroke direct fuel inject free piston generator from theory to practice", ARPN Journal of Engineering and Applied Sciences, 11(23), pp. 13486-13496 (2016).

41. Mahadi, W.N.L. and Adi, S.R. "Application of Nd2Fe14B magnet in the linear generator design", International Journal of Engineering and Technology, 4(2), pp. 175-184 (2007).

42. Wang, J., West, M., Howe, D., et al. "Design and experimental verification of a linear permanent magnet generator for a free-piston energy converter", IEEE Transactions on Energy Conversion, 22(2), pp. 299306 (2007).
43. Zulkifli, S.A., Karsiti, M.N., and Aziz, A.R.A. "Starting of a free-piston linear engine-generator by mechanical resonance and rectangular current commutation", In Vehicle Power and Propulsion Conference, Harbin (2008).

44. Eid, A.M., Suh, K.Y., Choi, K.J., et al. "A unique starting scheme of linear-engine tubular PM linear generator system using position feedback controlled PWM inverter", 37th IEEE Power Electronics Specialists Conference, Jeju (2006).

45. Rinderknecht, F. and Herzog, H.G. "Calculation of a linear generator for a hybrid vehicle concept", XIX International Conference on Electrical Machines (ICEM), Rome (2010).

46. Abdalla, I., Ramlan, N.A., Aziz, A.R.A., et al. "Free piston linear generator for low grid power generation", In MATEC Web of Conferences, 131, pp. 1-12 (2017).

47. Sun, P., Zhang, C., Chen, J., et al. "Decoupling design and verification of a free-piston linear generator", Energies, 9(12), pp. 1-23 (2016).

48. Pavelka, J. "Analysis of combustion engine-electric linear generator set operation", 13th In Power Electronics and Motion Control Conference, Poznan (2008).

49. Arof, H. and Ping, H.W. "Analysis of magnetic field distribution of a cylindrical discrete Halbach permanent magnet linear generator", IET Electric Power Applications, 4(8), pp. 629-636 (2010).

50. Rerkpreedapong, D. "Field analysis and design of a moving iron linear alternator for use with linear engine", PhD Thesis, West Virginia, USA (1999).

51. Xu, Z. and Chang, S. "Improved moving coil electric machine for internal combustion linear generator", IEEE Transactions on Energy Conversion, 25(2), pp. 281-286 (2010).

\section{Appendix}

Code translation between ANSYS Maxwell 3D Magnetostatic and MATLAB GUI software was given an online source. The link is: https://docs. google.com/document/d/11LKAdCBWZJVDqOCXIz BVAwTqIDxuph-PFx36DYtlo9Q/edit?usp=sharing

\section{Biographies}

Serdal Arslan received the $\mathrm{MSc}$ and $\mathrm{PhD}$ degrees in Electrical Education from the Institute of Natural and Applied Sciences, University of Gazi, Ankara, Turkey in 2011 and 2017, respectively. He worked as a Research Assistant at Hakkari University between 2010 and 2011. Then, he attended Harran University. He is currently an Assistant Professor at the Department of Electrical Technology, Harran University. He has been working on computational electromagnetic for many years. His research interests are in the areas of design, modeling, and analysis of electrical machines, 
optimization design of linear/rotary machines, and electromagnetic devices.

Osman Gürdal received the BSc and MSc degrees in Electrical Education from Technical Education Faculty, the University of Gazi, Ankara, Turkey in 1985 and 1991, respectively. He received the $\mathrm{PhD}$ degree in
Electrical \& Electronics and Computer Engineering from the University of Sussex, Brighton, UK in 1994. After 27 years of academic life at the University of Gazi, He is now a Professor at the Ostim Technical University. His research interests are in computer-aided design, analysis and simulation of electrical machines, magnetic circuits and actuators, and field theory. 